\title{
A LINGUAGEM POLÍTICA DOS FOROS DE CASTELO RODRIGO. IDENTIDADE E EXCLUSÃO NO CONTEXTO MUNICIPAL \\ (RAIA LUSO-LEONESA: SÉCULO XIII) ${ }^{1}$
}

\author{
Rui CUnHA MARTINS \\ Universidade Católica Portuguesa
}

SUMARIO

1. A escrita (ou a fixação da desigualdade). - 2. A gestão das tensões (ou a construção da identidade).- 3. A gestão da alteridade (ou a outra face da construção da identidade).- 4 . O espaço (ou a projecção das clivagens).

A crer em determinada leitura evolutiva do sistema concelhio, este seria marcado, em termos socio-políticos, pela passagem de um período (a segunda metade do século XII e os inícios do XIII) de "quiebra progresiva de las estructuras unitarias de los concejos" a um outro (os meados do século XIII) que consuma a tendência anterior e assiste ao "triunfo de las élites"2.

'Uma primeira versão deste trabalho foi apresentada à mesa-redonda sobre "Identidade e Exclusão em perspectiva histórica" (Dezembro, 1996), promovida pelo então recém-criado Grupo de Estudos Interdisciplinares.

${ }^{2}$ José Maria Monsalvo AnTón, Transformaciones sociales y relaciones de poder en los concejos de frontera, siglos XI-XIII. Aldeanos, vecinos y caballeros ante las instituciones municipales, in "Relaciones de poder, de producción y parentesco en la Edad Media y Moderna. Aproximación a su estudio", Madrid, 1990, pp. 107-170, esp. 111-115. O Autor refere-se ao caso concreto dos concelhos de fronteira. Segundo ele, a afirmação de determinados rasgos característicos desses concelhos enquanto centros de poder, enquanto efectivos sistemas políticos, não aconteceria antes dos meados do século XIII, ou seja, antes da fixação de uma série de tendências prenunciadas já no século anterior (disponibilidade de um pessoal político próprio; exercício de poderes estatais de forma soberana; extensão da autoridade concelhia sobre um âmbito territorial e jurisdiecional específico...) e que permitiriam agora, uma vez

"Anuario de Estudios Medievales". 27 (1997) 
Esta linha interpretativa pode servir de pórtico ao presente estudo, na medida em que permite contextualizar a documentação que serve de base à nossa análise, os foros extensos. Dado que no espaço luso-leonês a generalização destas compilações municipais ocorre precisamente durante o século XIII, é de aceitar que elas expressem de alguma forma as tendências atrás aludidas; mais: que elas sejam um dos pilares em que assenta a consolidação dessas tendências. E que, a confirmarem-se semelhantes pressupostos, seja possível analisar os foros não apenas enquanto repositórios de arcaísmos e de permanências, que também são, mas igualmente em termos prospectivos, procurando entendê-los como indicadores de determinado panorama concelhio que a Baixa Idade Média consagrará mas que se vem construindo já nos séculos anteriores.

Assim sendo, o percurso analítico a desenvolver aqui sobre os foros deverá girar em torno da seguinte questão: de que mecanismos se serve, quer dizer, que disposições acolhe essa documentação municipal, para assegurar, no contexto do século XIII, a reprodução e a maturação de determinado quadro socio-político? Ou, dito de outro moudo, de que forma os foros extensos "son sensibles a las exigencias que el sistema social plantea al sistema político"? $?^{3}$

As reflexões que se seguem constituem, de alguma maneira, a tentativa de dar resposta a essa questão. Com base nos foros de Castelo Rodrigo, mas sem abdicar, sempre que fôr caso disso, do recurso a analogias e confrontos, quer com os restantes foros da mesma família, quer com os foros da Extremadura leonesa, quer até com os foros e costumes do centro e sul de Portugal ${ }^{4}$, procurar-se-á equacionar o problema à escala da

conjugadas, fazer dos concelhos verdadeiras instâncias de soberania, capazes de concorrer com os outros poderes políticos feudais.

${ }^{3}$ IDEM, Ibidem, p. 132, nota 39.

${ }^{4}$ Para os foros de Castelo Rodrigo: Luís Filipe Linder CinTRA, $A$ linguagem dos foros de Castelo Rodrigo. Seu confronto com a dos foros de Alfaiates, Castelo Bom, Castelo Melhor, Coria, Cáceres e Usagre. Contribuição para o estudo do leonês e do galego-português do século XIII, $2^{\mathrm{a}}$ ed. Lisboa, 1984 ( $1^{\mathrm{a}}$ ed. Lisboa, 1959). Para os foros de Alfaiates, Castelo Bom e Castelo Melhor: Portugaliae Monumenta Historica. Leges et Consuetudines, I e II, Lisboa, 1856-1858. Para os casos de Coria, Cáceres e Usagre, vejam-se, respectivamente: José MALDONADO Y FERNÁNDEZ DEL TORCO (estudio histórico-jurídico) y Emilio SÁEZ (transcripción y fijación del texto), El Fuero de Coria, Madrid, 1949; Pedro Lumbreras Valiente, Los fueros municipales de Cáceres. Su derecho publico, Cáceres, 1974; Rafael de UREÑA y Adolfo Bonilla, Fuero de Usagre (siglo XIII), anotado con las variantes del de Cáceres, Madrid, 1907. Para os foros leoneses: Américo CASTRO y F. de ONís (ed. y estudio), Fueros leoneses de Zamora, Salamanca, Ledesma y Alba de Tormes, I, Madrid, 1916 (Veja-se, para o caso de 
raia luso-leonesa no século XIII. Convém notar que não se trata tanto de procurar uma renovada visão sistemática sobre os foros e costumes municipais (aliás, desse ponto de vista, dispomos das sínteses de José Mattoso, Maria Helena Coelho e José Luis Martín, bem como dos incontornáveis trabalhos de José María Monsalvo ${ }^{5}$ ) quanto, fundamentalmente, de trabalhar sobre eles alguns problemas e conceitos -designadamente as formas de identidade e de exclusão- susceptíveis de nos conduzir à descodificação da sua linguagem socio-política.

\section{A ESCRITA \\ (OU A FIXAÇÃO DA DESIGUALDADE)}

Colocados do ponto de vista do século XIII, podemos começar por tomar como dado adquirido, como legado da evolução anterior, a desigualdade de base que então sustenta, de forma declarada, o sistema concelhio. É bem conhecido o clássico quadro: predomínio dos cavaleiros-vilãos, acompanhado pela inferioridade dos peões e pela existência de um numeroso grupo de dependentes praticamente sem regalias ${ }^{6}$. Deixemos mais para diante a tarefa de avaliar do grau de operatividade ainda detido pela lógica

Salamanca, uma edição mais recente: José Luis MARTín e Javier CocA, Fuero de Salamanca, Salamanca, 1987). Os costumes da Guarda, S. Martinho de Mouros, Torres Novas, Santarém, Beja e Gravão estão publicados em Inéditos de História Portugueza, Lisboa, Academia Real das Sciencias, IV e V, 1916-1924. Ver ainda os costumes, derivados de alguns deste últimos, comunicados a Vila Nova de Alvito, Oriola, Alcácer, Alcáçovas e Terena: Portugaliae Monumenta Historica. Leges et Consuetudines, II vol., Lisboa, 1858.

${ }_{5}^{5}$ José MAtToso, Identificação de um País. Ensaio sobre as origens de Portugal, I, Lisboa, 1985, pp.291 ss.; IDEM, Da comunidade primitiva ao município. O exemplo de Alfaiates, in "Fragmentos de uma composição medieval", Lisboa, 1987, pp. 35-48; IDEM, Grupos sociais na fronteira portuguesa, sécs. XI a XIII, in "Las sociedades de frontera en la España medieval", Zaragoza, 1993, pp. 111-124; Maria Helena da CruZ CoelHo, Concelhos, in M. H. da CruZ Coelho e A. L. de Carvalho Homem (coord.), Portugal em definição de fronteiras. Do Condado Portucalense à crise do século XIV, vol. III da "Nova História de Portugal" dir. por J. SERRÃo e A.H. de OliveIRA MARQues, Lisboa, 1995, pp. 554-584 (veja-se também o cap. $O$ Povo. A identidade e diferença no trabalho, in IDEM, ibid., pp. 252-308. Não sendo ambos os capítulos dedicados exclusivamente aos foros extensos, essa documentação serve contudo de base à síntese feita); José Luis Martín, "Los fueros: normas de convivencia y trabajo", in J. L. MarTín (dir.), Historia de Salamanca, II: La Edad Media (coord. J. M. MíngUEZ), Salamanca, 1997, pp. 74-124. Dos trabalhos de J.M. MonSALvo cite-se, a título de exemplo: La organización concejil en Salamanca, Ledesma y Alba de Tormes (siglo XII-mediados del siglo XIII), in "I Congreso de Historia de Salamanca" (1989), I vol., Salamanca, 1992, pp. 365-395. ss.

${ }^{6} J$ osé Mattoso, op. cit, pp. 347-378, Maria Helena da Cruz Coelho, op. cit., pp. 253 
de diferenciação cavaleiro-peão no período cronológico que nos ocupa. O que importa, de momento, é registar que, se por um lado o papel da desigualdade enquanto critério de ordenação social parece nesta altura inquestionável, então, por outro lado, o problema que se coloca é o da sua preservação, é o de verificar de que modo se assegura a reprodução dessa desigualdade. Ora, tal pode ocorrer de diferentes formas. A escrita, desde logo, não é uma técnica inocente neste contexto ${ }^{7}$.

Diz J. Goody que a introdução da escrita "ajuda a explicitar o implícito"8. A uma vontade de explicitação terá correspondido, por certo, a preocupação dos grupos sociais dominantes à escala concelhia em compilar os costumes municipais durante o século XIII. Em garantir, pela sua redacção, a fixação de uma série de disposições e regras até então mais ou menos implícitas e que agora, sob uma supervisão tolerante do poder central, conhecem novo fôlego, e, em qualquer caso, maior eficácia pelo simples facto da sua passagem a escrito. Eficácia, entenda-se, do ponto de vista dos grupos sociais mais implicados nos foros extensos - os cavaleiros-e que, por esse motivo mesmo, se apresentam como seus principais benificiários, ao ponto de os foros parecerem redigidos "para si e por si".

Trata-se, pois, da tentativa de preservação de determinado posicionamento na comunidade, o que faz com que "os costumes tomem o ponto de vista dos cavaleiros"9 e que a sua passagem a escrito constitua afinal, também ela, um dos mecanismos de reprodução da diferença e da desigualdade em que já assentava, por alturas da compilação, a estrutura concelhia. Pouco importa, nesta perspectiva, que os foros e costumes recolham textos anteriores, até escritos, e sejam o resultado de diversos momentos e cronologias. O que conta mesmo é a compilação, é esse momento impreciso do século $\mathrm{XIII}^{10}$ em que se concretiza a ideia de redigir todo esse material

\footnotetext{
${ }^{7}$ Para un enquadramento das questões sociais decorrentes da escrita, veia-se Maria José Azevedo Santos, A evolução da língua e da escrita, in Portugal em definição de fronteiras, vol. III da "Nova História de Portugal" (dir. J. SERRẢo e A.H. Oliveira Marques), Lisboa, 1995, pp. 604-634.

${ }^{8} \mathrm{Jack}$ Goody, La lógica de la escritura y la organización de la sociedad, trad. esp. Madrid, 1990 (ed. orig. ingl. Cambridge, 1986), p. 211.

${ }^{9}$ José Mattoso, Identificação de um País, I, pp. 379 (ver também pp. 352-353).

${ }^{10}$ Sobre a data da redacção dos foros de Castelo Rodrigo, ver Luís Filipe LinDLEY CINTRA, op. cit., pp. XCIV-CII. E também Gonzalo MARTÍNEZ DíEZ, Los fueros de la familia CoriaCima-Coa, "Revista Portuguesa de História", 13 (1971), pp. 343-373. Ainda: J.A. DuARTE NogueIRA, A organização municipal da Extremadura leonesa nos sécs. XII e XIII, "Boletim da Faculdade de Direito de Coimbra", nesp. (1983), pp. 3-61, esp. 4-18.
} 
oral e escrito num todo. Até porque, seguramente, a compilação supõe uma selecção, e esta, por seu turno, um critério. Tudo indica que foi seguido o dos cavaleiros.

É como se se procurasse um "efeito de espelho", à maneira de Joaquim Pais de Brito", em que os costumes municipais são agora o "espelho" onde se revê o concelho, onde interessa que ele se reveja, por forma a que a comunidade incorpore a imagem social veiculada nos foros como se de uma projecção reflectida da sua própria imagem se tratasse. Em última instância, é a redacção dos foros que permite "devolver" ao concelho uma imagem de si próprio enquanto sistema orgânico, sendo que a construção dessa imagem é manipulada por franjas sociais específicas, capacitadas para impôr a sua lógica como modelo comportamental e referencial à restante população.

Não será ocioso frisar que, nesta perspectiva, este tipo de legislação municipal não deverá ser entendido apenas como o reflexo da realidade social e política concretas do espaço concreto ao qual se aplica, mas também (sobretudo?) como uma proposta de agir sobre essa realidade ${ }^{12}$.

\section{A GESTÃO DAS TENSÕES (OU A CONSTRUÇÃO DA IDENTIDADE)}

Falámos de desigualdade. E, contudo, por paradoxal que possa parecer, uma boa parte do discurso dos foros constrói-se em torno da igualdade, podendo uma leitura menos atenta do conjunto de prescrições normativas sugerir até alguma preocupação em nivelar os comportamentos da comunidade. Na verdade, essa sensação de nivelamento não é totalmente ilusória. Deriva, por um lado, da situação a que já fizemos referência quanto ao carácter que preside à redacção dos foros e que leva à prevalência, no conteúdo dos mesmos, da lógica organizativa do grupo dos cavaleiros, aos quais respeitam, em fim de contas, a maioria das prescrições aí contidas; e

\footnotetext{
"Joaquim PAIS DE BRITO, Retrato de Aldeia com Espelho. Ensaio sobre Rio de Onor, Lisboa, 1996, pp. 18-19.

${ }^{12} \mathrm{Ou}$, para o dizer com Clifford Geertz, "law is constructive of social life not reflective, or anyway not just refective" (C. GEERTZ, Local knowledge: fact and law in comparative perspective, in "Local knowledge. Further essays in interpretative anthropology", New York, 1983, p. 218).
} 
deriva, por outro lado, do facto de estes últimos contraporem à desigualdade de base que preside ao relacionamento social entre si e a peonagem, uma série de mecanismos de solidariedade, ou, pelo menos, de apaziguamento das diferenças, a desenvolver, exclusivamente, no âmbito dessa minoria que controla os destinos concelhios ${ }^{13}$.

Busca de equilíbrio entre iguais - assim se pode definir a preocupação que esta aristocracia local deixa escapar para os foros. Claro: não se procura o equilíbrio senão à custa de uma meticulosa gestão das tensões. Mas é justamente aí, nesse equilíbrio instável, que assenta a incorporação, pelo grupo, de uma consciência identitária, ainda quando essa identidade se cinge, afinal, à procura de manutenção da posição alcançada pelo grupo, a fazer coincidir essa supremacia alcançada com a ideia de "interesse comum", e a dar assistência, para tanto, a uma série de normas neutralizadoras das tensões internas; numa palavra, a privilegiar ferozmente a ordem, despromovendo o conflito.

De um ponto de vista teórico, há que acentuar o facto de a evidente precaridade do equilíbrio assim conseguido não ser factor impeditivo da celebração da ordem e da procura da estabilidade. O próprio Talcott Parsons, a quem tradicionalmente se atribui um pendor consensualista na análise social, assinalou a propensão de qualquer sociedade para a manutenção de "um estado relativamente precário de equilíbrio em movimento ${ }^{14}$, assim reconhecendo um nível de interacção dialéctica entre a estática e a dinâmica e abrindo campo à consideração dos mecanismos tensionais em qualquer arrumação social. De resto, como recorda a este propósito Seymour Martin Lipset, o próprio conflito tem "consequências integradoras"15, concerteza em virtude de despoletar a necessidade da sua gestão.

De um ponto de vista concreto, o problema que então se coloca é o de saber que formas revestiu, precisamente, essa necessária gestão de tensões, essa procura de equilíbrio no seio do grupo privilegiado. Neste aspecto, aceita-se que o panorama detectado para Castelo Rodrigo reproduza linhas de força já conhecidas: uma implícita redistribuição dos bens (hipoteticamente também dos cargos) pelos vários componentes do grupo, ou, mais

\footnotetext{
${ }^{13}$ Ver, sobre isto, os vários trabalhos de J. MAtroso atrás citados.

${ }^{14}$ Talcott Parsons, The Social System, Nova Iorque, 1951, p. 535, cit. por Seymour MarTin LIPSET, Consenso e Conflito, trad. port. Lisboa, 1992 (ed. orig. ingl. New Jersey, 1985), p. 33.

${ }^{15}$ Seymour MARTIN LIPSET, op. cit., p. 27.
} 
correctamente, pelos vários grupos de parentes convivendo no âmbito do grupo privilegiado, por forma a evitar concentrações de fortuna e poder perturbadoras do equilíbrio; e um rígido enquadramento dos indivíduos em assuntos de justiça, única forma considerada adequada para fazer frente às situações de tensão despoletadas no contexto de uma sociedade potencialmente violenta. Ou seja: que reproduza, com pequenas atenuantes, o quadro detectado por José Mattoso para Alfaiates.

Com efeito, também em Castelo Rodrigo é possível observar uma série de normas idênticas às que ele estudou, as quais, se nem sempre expressam directamente aquelas linhas de força, subentendem uma lógica de funcionamento com essas características. Assim, por exemplo, a importância tomada pelo parentesco deve deduzir-se não apenas das referências declaradas aos mecanismos sucessórios ${ }^{16}$ mas também, e sobretudo, da possibilidade conferida à parentela de se constituir em sede de justiça, paralelamente, ou antes mesmo, da actuação dos mecanismos judiciais concelhios, bastando para tal que um elemento do grupo de parentes esteja envolvido no conflito. Por ser assim, o homicídio não omite, em Castelo Rodrigo, um nível de resolução parenteral, devendo os parentes do homicida fazer doação de todos os bens deste aos parentes do morto e considerar o assassino, a partir desse momento, como seu próprio inimigo ${ }^{17}$. Aliás, esta necessidade de apaziguar os focos de conflito latentes leva mesmo a declarar o homem que tiver morto outro como inimigo, em simultâneo, "de seus parentes e do concelho"18, assim se procurando salvaguardar tanto a orgânica judicial concelhia quanto o regular funcionamento das solidariedades parentais que lhe subjazem. A mesma preocupação, de resto, que se percebe do cuidado posto com as alianças matrimoniais, punindo a mulher

\footnotetext{
${ }^{16}$ Os quais, significativamente - como o notou Guilherme BRAGA DA CRUZ, O Direito de Troncalidade e o regime jurídico do património familiar, tomo II. Braga, 1947, pp. 361-362manifestam alguma diversidade consoante se consultam os diferentes foros de Riba-Coa (sendo que os de Castelo Rodrigo transportam parca informação quanto a este aspecto). Ora, sabendose que por norma os vários foros ribacudanos tendem a coincidir na maioria das suas disposiçōes. esta constataçāo quanto à peculiaridade de alguns mecanismos sucessórios parece traduzir uma particular atenção do redactor dos foros para com a situação concreta do respectivo concelho, reafirmando assim. ainda mais, a transcendência da lógica do parentesco na organização social.

${ }^{17}$ Foros de Castelo Rodrigo, III,12: "Tod omne que autro matare $[\ldots]$ sio non poderen aver, den toda sua bona aos parentes do morto; e quando deren toda sua bona, iuren $\mathrm{V}$ de seus parentes, os mellores, que mas benes non avia; e denlo que seia inimigo." Veja-se também, no mesmo sentido: Idem, III, 24 e Idem. III, 25.

${ }^{18}$ Foros de Castelo Rodrigo, III, 23.
} 
"que tomar marido sem [o consentimento dos] seus parentes" e dando por inimigo aquele que nessas condições a tomar por mulher ${ }^{19}$, por forma a impedir a viciação de um processo que, pelas sua óbvias repercussões económicas, era susceptível de perigar o equilíbrio material no seio do grupo e devia por isso ser resolvido no âmbito familiar.

Mas talvez o mais claro indicador do que temos vindo a chamar "equilíbrio precário" seja a figura ambígua dos alcaldes e das disposições previstas para a sua actuação em matéria judicial. Deixando de lado as poucas e tímidas referências ao juíz (aspecto que alinha os foros de Castelo Rodrigo com os outros costumes ribacudanos) ${ }^{20}$, e porque é sobre os alcaldes que assentam a maior parte das responsabilidades no tocante ao exercício da justiça concelhia, não pode deixar de assinalar-se a intenção dispositiva de conferir à sua actuação um recorte de gestor de tensões, muito mais do que atribuir-lhe funções excessivamente decisórias. Daqui decorre a ambiguidade patente no exercicio do cargo. Não falando já das situações tensionais resolvidas pela "justiça familiar" e que pressupõem, obrigatoriamente, a secundarização da justiça concelhia representada pelos alcaldes e mesmo a sua total ausência ${ }^{21}$, é também possível deparar com situações em que, prevendo-se embora a sua presença, são obrigados a conviver com outros mecanismos de controlo, ou ainda com disposições normativas que lhes estipulam meras funções de arbitragem na resolução dos conflitos ${ }^{22}$. $\mathrm{Na}$ realidade, aquilo que assim nos aparece, a pretexto dos alcaldes, como um quadro de competências sobrepostas ou concorrenciais, não é mais do que o reflexo de diferentes "âmbitos de participação política" -para utilizar a proposta analítica de J.M. Monsalvo- no âmbito dos quais a esfera dos cargos municipais, entendida como a instância política mais restrita e selectiva, não dispensa ainda (no contexto dos foros) a actuação de níveis de competência menores, tais os protagonizados por juntas, homens bons ou

\footnotetext{
${ }^{19}$ Foros de Castelo Rodrigo, IV, 1: "Moller que sola tomar marido, sin seus parentes, seia desheredada; e quena tomar, seia inimigo. Vibda tome marido qual se queser, con seus parentes: Manceba orfana, hos parentes de anbas partes la casen. E, se parentes dela una parte la casaren, quila la casar yxca inimigo e peyte couto alos outros parentes, como sila matasse".

${ }^{20}$ José Mattoso, Identificação de um País, I, p. 433. Para o caso concreto do pouco relevo atribuído ao juíz em Castelo Rodrigo, vejam-se os respectivos foros: VIII, 16 e VIII, 18

${ }^{21}$ Foros de Castelo Rodrigo, III, 12; III, 28.

${ }^{22}$ Como acontece de forma clara no extenso título III, 39 bis dos foros de Castelo Rodrigo, relativo aos lidadores.
} 
jurados, para evocar apenas o segmento participativo social e políticamente mais próximo das magistraturas, e com o qual estas se articulam ${ }^{23}$.

Estes aspectos relevam, por conseguinte, da necessidade sentida pelos grupos dominantes de equilibrar o relacionamento entre si. Vimos já que a simples prossecução desse objectivo, ao obrigar à gestão das tensões internas visando a preservação do estatuto de supremacia adquirido, fomentava os vectores de integração e, previsívelmente, a "construção" de uma identidade de grupo. Esta, porém, difícilmente seria consolidada apenas a partir de dentro, pelo simples facto de que a própria ideia de identidade pressupõe a existência do diferente para com ele interagir. Neste sentido, a procura de equilíbrio interno cumpria apenas parte do esforço necessário à reprodução social da camada dominante nos concelhos; tão importante quanto isso era desenvolver, em paralelo, os mecanismos de diferenciação face à restante população, face a uma realidade múltipla à qual os grupos dominantes se opunham agora como um todo, ainda que também ele intrínsecamente instável. É que a identidade não se alcança senão frente à alteridade -e a aristocracia concelhia não podia, por esse motivo, descurar a "construção do outro". Dito de outra forma, a produção de uma identidade inclusiva teria de ser acompanhada, em complementaridade, pela produção de uma identidade exclusiva ${ }^{24}$.

\section{A GESTÃO DA ALTERIDADE \\ (OU A OUTRA FACE DA CONSTRUÇÃO DA IDENTIDADE)}

Gerir a diferença, no caso da comunidade instalada em Castelo Rodrigo no século XIII, parece ter passado pela existência de dois níveis de diferenciação sobrepostos. Desde logo, pela subordinação. Da massa heterogénea dos dependentes para com os cavaleiros, mas também dos peões relativamente a este últimos, ou, o que não é mais do que evocar de outra forma o sentido da distinção anterior, dos habitantes do termo frente aos interesses dos homens da vila, por entre muitas outras hierarquizações

\footnotetext{
${ }^{23}$ Ver J.M. Monsalvo, La organización concejil en Salamanca, pp. 376-393.

${ }^{24}$ Conceitos que colhemos de Filomena Silvano, Territórios da Identidade, Oeiras, 1997. p. 146. Dessa obra se colhe também a sugestão de substituir a ideia de identidade pela de identidades múltiplas, tendo em conta que "os indivíduos identificam-se com uma multiplicidade de figuras" (p. 2).
} 
possíveis de estatuto e de poder. Mas, sobretudo, a aposta na desigualdade traduziu-se e foi garantida pela exclusão, quer dizer, pela prática do fechamento tendencial do grupo preponderante, ainda que quantitativamente minoritário, sobre si próprio, por forma a ocasionar, por inerência, a inferiorização dos elementos considerados exteriores, sobre os quais se faz pender uma série de limitações que os definem fundamentalmente em termos de inferioridade, por comparação com os privilégios consignados ao grupo dominante. Desse ponto de vista, a inferiorização denunciada pelos foros não é senão a evidência de um processo de exclusão.

Importa agora equacionar estas questões ao nível concreto espaciotemporal em que nos movemos. Convém notar, entretanto, que não é nossa intenção proceder aqui ao levantamento sistemático de todos os factores de diferenciação e exclusão de que dão conta os costumes de Castelo Rodrigo (cujo panorama não se afasta significativamente, a esse nível, do detectado por Maria Trinidad Gacto Fernández para o contexto da Extremadura leonesa ${ }^{25}$ ). Não é pois questão de discutir aqui os critérios socio-jurídicos que eventualmente presidam ao escalonamento social; interessa-nos, isso sim, chamar a atenção para a diversidade de perfis tomados pela "construção do outro" a que atrás nos referimos, à margem de qualquer proposta de classificação jurídico-formal.

Assim, por entre "os outros" da aristocracia local, por entre aqueles elementos ou grupos de que ela se diferencia, excluíndo-os e/ou submetendoos, encontramos quer os casos mais clássicos, chamemos-lhe assim - peões (tradicionalmente opostos aos cavaleiros), não vizinhos (podendo tratar-se de simples "moradores", dos aldeãos do termo ou até de indivíduos de fora, exteriores ao concelho, opostos, uns como outros, aos que disfrutavam do estatuto de vizinho), dependentes (para os quais faz mais sentido falar de submissão, relativamente à aristocracia concelhia, do que de exclusão), ou grupos inferiorizados por motivos étnico-religiosos, tais judeus e mourosquer casos de ocorrência mais pontual, tal como sucedia, por exemplo, com os indivíduos caídos em desgraça pela lógica da justiça parental e condenados a uma rígida inimizade.

\footnotetext{
${ }^{25}$ Maria Trinidad GACTO FERNÁNDEZ, Estructura de la población de la Extremadura leonesa en los siglos XII y XIII (Estudio de los grupos socio-jurídicos, a través de los fueros de Salamanca, Ledesma, Alba de Tormes y Zamora), Salamanca, 1977. Consulte-se ainda, a este propósito: Alberto GARCía ULECIA, Los factores de diferenciación entre las personas en los fueros de la Extremadura castellano-leonesa, Sevilla, 1975.
} 
Abdicando da exaustividade neste arrolamento, até porque o inventário dos casos possíveis poderia prolongar-se, fiquemos com aquelas que são talvez as duas situações de diferenciação mais operativas: a inferiorização da peonagem frente ao grupo dos cavaleiros e os mecanismos diferenciadores decorrentes do conceito de vizinhança.

A oposição entre cavaleiros e peões é concerteza uma das mais emblemáticas dos concelhos de Riba-Coa. Nem por isso é a mais retratada, já que as referências aos peões apenas surgem episodicamente ao longo dos foros. Ao que tudo indica, as menções que lhes consagram os de Castelo Rodrigo são ainda mais escassas do que, por exemplo, as que aparecem nos de Alfaiates ${ }^{26}$. Em ordem a justificar esta "ausência" da peonagem, deve recordar-se não só o facto, já atrás evocado, de os foros serem redigidos na perspectiva dos cavaleiros (mais interessados em consignar as obrigações de jugueiros e solarengos, homens na sua dependência directa, do que em legislar sobre os peões), como também a provável redundância que constituiría, na primeira metade do século XIII, fixar ainda um estatuto dos peões que o século anterior se havia encarregado de clarificar e de normalizar, tornando agora como que desnecessário o seu registo.

Seja como fôr, estes aspectos não podem invalidar a hipótese de que a mediocridade de menções se possa interpretar, também, como o resultado de uma efectiva perca de importância, já na primeira metade do século XIII, da lógica distintiva cavaleiro-peão, provavelmente suplantada - caso se desenvolvam em Castelo Rodrigo tendências semelhantes às detectadas a um âmbito mais genérico ${ }^{27}$ - por outro tipo de modalidades de diferenciação, de menor conotação guerreira, ainda que reproduzindo em termos materiais e de prestígio a mesma separação hierárquica.

Com efeito, e sempre do ponto de vista do século XIII, mais operativa nos aparece a fissura trazida à sociedade concelhia pela noção de vizinhança. De entre os "outros" da aristocracia local, o não vizinho, e, logo, a distinção entre o vizinho e aquele que o não é, é concerteza a figura mais bem regulamentada. É bem verdade que a definição do seu estatuto não

\footnotetext{
${ }^{26} \mathrm{~A}$ título de exemplo, do qual ignoramos a respectiva representatividade efectiva, mencionese a prescrição de Alfaiates, citada por José MATTOSO, Identificação de uim País, I, pp. 361, quanto à articulação entre os cavaleiros e o número correspondente de peões por ocasião de algum combate. $\mathrm{O}$ assunto, ainda que presumivelmente importante, não é sequer aflorado no caso de Castelo Rodrigo.

${ }^{27}$ Para um enquadramento deste problema, José Maria MONSALvo ANTÓN, Transformaciones sociales y relaciones de poder, $\mathrm{pp}$. 153-170.
} 
surge exposta de forma completa nos foros, mas as referências indirectas - designadamente as que fazem depender a vizinhança da detenção de casa povoada na vila $^{28}$ e da posse de determinada fortuna ${ }^{29}$ - sugerem com razoável segurança uma situação próxima da dos concelhos leoneses, em que à capacidade económica e, logo, tributária, se juntam a detenção de propriedade e a residência no concelho (que, pelo menos em Castelo Rodrigo, tende a confundir-se com a residência na cabeça do concelho ${ }^{30}$ ) como elementos necessários à fruição do estatuto de vizinho ${ }^{31}$.

Por outro lado, o carácter socialmente distintivo da vizinhança está patente na maior consideração que merece o vizinho quando oposto ao aldeão: os dez morabitinos a pagar por todo aquele que deitar do cavalo abaixo um vizinho, descem para apenas dois morabitinos no caso de o descavalgado ser um aldeão ${ }^{32}$. E, sobretudo, do ponto de vista das capacidades políticas que se reconhecem aos indivíduos pertencentes à comunidade, não custa também perceber a desigual estima que merecem os vizinhos e os que o não são, dado que tudo aponta para que só aqueles tivessem acesso aos cargos municipais. Embora em pequeno número, as informações fornecidas pelos foros a este nível não deixam dúvidas quanto ao modo como o critério da vizinhança filtra o acesso às magistraturas, excluindo cabalmente todos os que não são vizinhos ou, o que vai dar no mesmo, todos os que, por não deterem a quantia necessária para o ser, ficam automaticamente excluídos ${ }^{33}$.

\footnotetext{
${ }^{28}$ Foros de Castelo Rodrigo, V, 74: "Qual quer omne de Castel Rodrigo que en na villa tovere casa poblada con omne que coma seu pan e faça seu servicio, dé seu dezmo e primicias ena vila e hi faça toda sua fazendeyra e aia foro assi como vizinnos de vila". E também: Idem, II, 27.

${ }^{29}$ Foros de Castelo Rodrigo, V, 66: "Qui valia overe de X mor. e non fore escripto en carta e en padron, nos seia vizinno a foro ni tome portelo ni firme sobre outro".

${ }^{30}$ Foros de Castelo Rodrigo, II, 27 (trata-se aqui de uma referência explícita) e VII,19 (referência agora indirecta, que passa pela associação morador da vila-vizinho).

${ }^{31}$ Sobre as condições de acesso à vizinhançăa: Maria del Carmen Carlé, Del concejo medieval castellano-leones, Buenos Aires, 1968, pp. 81ss. Ver também as consideraçôes posteriores de Maria Trinidad GaCTO FERnÁNDEZ, op. cit., pp. $33 \mathrm{ss}$. Em qualquer dessses trabalhos se encontra também referência à designação de "morador" e seu significado como não vizinho. A'oposição entre esse estatuto/designação e o de vizinho, que não merece aqui a nossa particular atenção, surge também nos foros de Castelo Rodrigo: III, 39 bis; III, 40 bis.

${ }^{32}$ Foros de Castelo Rodrigo, III, 11.

${ }^{33}$ Foros de Castelo Rodrigo, V, 23: "Tod omne que non fore escripto en carta e encomendado a sua colacion al foro e faça todas suas dereyturas, non seia vizino ni aia portelo". (itálico nosso). E, no mesmo sentido: Idem, V, 66.
} 
A exclusão, portanto. Demetrio Velasco chama a atenção para o facto de que "conceptos como nacionalidad, ciudadanía, extranjero, etc., son construcciones destinadas a legitimar situaciones de "cierre" y de "exclusión" en las relaciones entre individuos y grupos [conduzindo ao surgimento] de un nosotros y de un ellos" ${ }^{134}$. Com todo o propósito se acrescentará, pela nossa parte, o conceito de vizinhança. Ele constitui, em termos da sociedade concelhia do século XIII, uma das ideias-chave que permite a gestão da diferença, legitimando a exclusão. O que faz da vizinhança, afinal, um dos mecanismos que assegura o funcionamento de um processo tão caro a Max Weber e de tão ingrata tradução como o de social closure, isto é, "um processo de subordinação em que um grupo monopoliza os privilégios pelo fechamento de oportunidades a outro grupo (...) definido como inferior e inelegível" ${ }^{35}$. Nesta perspectiva, o conceito de vizinhança surge com as mesmas propriedades, ainda que a um nível funcional diferente, que o de cidadania, tal como o trabalhou, para uma época posterior, Rogers Brubaker: internamente inclusivo, mas externamente exclusivo ${ }^{36}$. Mas, na perspectiva não menos lúcida da História Social, o que importa reter dos dados que sumariamente convocámos é o modo como, apelando aos referidos processos mas visando para lá deles, os foros extensos procuram afastar as aldeias para as margens dos sistemas de poder, como que procurando adequar essa limitação em termos de participação política à ja então inegável inferiorização social. O que permite, com base não só no caso de Castelo Rodrigo, duas constatações: a) o entendimento do século XIII, ou talvez da sua primeira metade, como o momento em que se consumam, relativamente às comunidades de aldeia, tendências que vinham bem de trás, desde a altura em que, seguindo A. Barrios, a organização repovoadora propiciara a instalação, sobre essas comunidades, dos aparatos de poder feudal, abrindo campo a uma indelével dependência campesina que favorecia tanto a titulares

\footnotetext{
${ }^{34}$ Demetrio Velasco, Raíces historico-ideológicas del "extranjero", in "El extranjero en la cultura europea de nuestros días", Bilbao, 1997, pp. 348-349.

${ }^{15}$ Raymond MURPHY, Social Closure. The theon of monopolization and exclusion, Oxford 1988, p. 8. Relativamente a Weber. as páginas relativas a comunidades "fechadas" e "abertas" surgem em Economía y Sociedad, 4 vols., trad. esp. México, 1944 ( $1^{\text {a }}$ ed. alemã: 1922) I vol., pp. 42-46, e II vol., pp. 11-13. 28-61.

${ }^{36}$ Rogers BrUbaKer. Citizenship and Nationhood in France and Germany, 2a ed. Cambridge (Mass.)-London, 1994 ( $1^{\text {a }}$ ed. 1992), pp. 21. Aliás, segundo Brubaker, o âmbito municipal surge como a dimensão por excelência onde vạ̃o maturando, durante séculos, as lógicas de exclusão que mais tarde o Estado reproduzirá também, agora à sua escala, consubstanciadas no conceito de cidadania (vejam-se as pp.21-72).
} 
de senhorios quanto a concelhos urbanos; b) a confirmação da relação próxima entre, por um lado, a generalização dos foros extensos e, por outro, a fase histórica da evolução concelhia em que o caminho para a elitização tem como etapa a "derrota" dos aldeãos - que parece antecipar uma fase de maior fechamento socio-político (pontualmente já expressa nos foros) em que os processos de exclusão resultarão de clivagens que não assentarão já em critérios demasiado abertos como o de vizinhança ${ }^{37}$

Assim, seja por via de um meticuloso enquadramento normativo que aspira a equilibrar as tensões no seio dos grupos predominantes, seja pelo potencial fechamento desses mesmos grupos em torno do predomínio conseguido, a aristocracia local parece já suficientemente madura para proceder, em seu benefício, à gestão das clivagens sociais à escala concelhia. Prova disso é o discurso sobre o espaço: é que a representação do espaço produzida pelos foros constitui, antes de mais, o "decalque" daquelas clivagens. Ou o seu substrato.

\section{O ESPAÇO \\ (OU A PROJECÇÃO DAS CLIVAGENS)}

Partimos, neste ponto, de um postulado já antigo que as representações do espaço são, de alguma forma, a tradução de determinado recorte social e que, assim sendo, é possível abordar a questão das identidades e da diferenciação social a partir do relacionamento que dada comunidade estabelece com o espaço. Ideias, no fundo, aceites desde há muito, desde os contributos de C. Lévi-Strauss ${ }^{38}$ até aos mais recentes de Christopher Tilley $^{39}$. (Mesmo se, a este nível, a nossa inspiração se dirige preferencialmente para uma abordagem de índole histórica: o lapidar tratamento

\footnotetext{
${ }^{37}$ Ver, para os conteúdos da alínea a), Ángel Barrios García. Repoblación de la zona meridional del Duero. Fases de ocupación, procedencias y distribución espacial de los grupos repobladores, "Studia Historica. Historia Medieval", III-2 (1985), pp. 33-82; e, para os da alínea b), J.M. MONSALvo ANTÓN, Transformaciones sociales, pp. 152-153.

${ }^{38} \mathrm{Em}$ particular ao evidenciar uma correspondência entre a diferenciação social e a diferenciação das representações do espaço: Claude LÉVI-STRAUSS, Tristes Trópicos, ed. port. Lisboa, 1979 ( $1^{\text {a }}$ ed. 1955).

${ }^{39}$ Sintetizados na ideia de que "space is socially produced": Christopher TILLEY, $A$ phenomenology of landscape. Places, paths and monuments, Oxford-Providence, 1994, pp. 10. Veja-se uma crítica ás teses de Tilley sobre o entendimento do espaço enquanto categoria analítica em Jorge de Alarcão, "A arqueologia contextualista", Máthesis, 6 (1997) pp. 11-32.
} 
efectuado por Carlos Estepa para o contexto castellano dos séculos XII e XIII e, em particular, a verificação de que "el papel del alfoz en la ordenación territorial es una de las contribuciones para expresar a nível geográfico las relaciones sociales propias del sistema feudal, signadas por la existencia de la dependencia") ${ }^{40}$.

No nosso caso concreto, merece particular destaque a forma como o discurso sobre o espaço contido nos foros se apresenta como um refoço das situações de diferenciação socio-política atrás apontadas. Com efeito, de acordo com os costumes municipais de Castelo Rodrigo, o espaço constitui, também ele, um critério diferenciador em potência, não sendo totalmente claro se a sua representação tem o efeito de duplicar os mecanismos sociais, sendo um produto deles, ou se, afinal, é sobre ele e a partir dele que se estruturam esses mecanismos de ordenamento social, parecendo, em todo o caso, evidente a interacção de ambas as funções. Dito isto, não é de estranhar que o espaço em causa nos surja claramente hierarquizado, nem que o traço mais óbvio dessa hierarquia seja a distinção entre o espaço da vila e o espaço do termo, onde se incluem as aldeias, opondo-se ainda a vila e o termo, agora em conjunto, ao espaço exterior ao concelho.

Podemos começar por distinguir, para melhor enquadrar as nossas reflexões a este respeito, entre espaço de pertença e espaço de referência, incluindo no primeiro o espaço da comunidade propriamente dito e no segundo as zonas exteriores à comunidade ${ }^{41}$. Ora, nesta perspectiva, o espaço de pertença subentendido pelos foros de Castelo Rodrigo não excede, em rigor, os limites da vila, com a qual tende a confundir-se; as zonas abrangidas pela designação de "termo", bem como o espaço aldeão, se bem que incluídos no espaço concelhio, correspondem a um círculo espacial distinto, porque hierarquicamente inferior, ao âmbito capitalino da vila. Não quer isto dizer que não houvesse consciência dos limites concelhios; essa consciência existe de facto ${ }^{42}$; ela não é, contudo, prioritária, sendo obrigada

\footnotetext{
${ }^{41}$ Carlos ESTEPA DíEz. El alfoz y las relaciones campo-ciudad en Castilla y León durante los siglos XII y XIII, "Studia Historica. Historia Medieval", II-2 (1984), pp. 7-26.

11 "As duas modalidades através das quais uma comunidade constrói o seu território" (Filomena Silvano, op. cit., p. 8).

42 Foros de Castelo Rodrigo, V. 74: " [...] E os que morarem enas aldeas en nosso termino, daquend' Agada e hy overen suas casas e hy moraren con fillos e con molleres las duas partes do anno, aian foro assi como vizinos de aldeas e hy den todas suas dereyturas; e hos que moraren de Agada allende...". Além disso. a própria existência de uma modalidade como o "medianido" ("a reunião dos magistrados de dois concelhos nas estremas dos respectivos
} 
a rivalizar com critérios delimitadores mais subtis mas profundamente axiais na hierarquização do espaço local. Tudo aponta, por conseguinte, para que se opere ao nível da representação do espaço uma clivagem idêntica à que uma análise dos mecanismos de organização social permitira já revelar. De um ponto de vista prático, esta hierarquia terá talvez a sua tradução mais evidente quando se estipula que "tod omne que [ouuer] aduzir [a] outro a plazo, adugalo, de vila, a outro dia, e de aldeas e de nostro termino, a tercer dia, e fora de nostro termino, a IX dias, silo poder aver" ${ }^{43}$.

De resto, com maior ou menor grau de rigidez, a distinção entre a vila e as aldeias está constantemente presente ao longo dos foros, constituindo um dos seus rasgos mais evidentes. O mecanismo é sempre idêntico. $\mathrm{O}$ critério distintivo de base socio-jurídica funciona em sintonia com o critério espacial de diferenciação: "qui ronpire en villa casa ou corral de vizino con armas, peyte .L. mor. [e] qui ronpire casa de vizino de vila en aldea ou corral ou moyno o açenna ou colmenar ou cabana, peyte .X. mor." ${ }^{44}$. Tanto, ou mais, do que uma diferenciação entre pessoas, está em causa uma distinção com base no espaço a que elas estão adscritas, motivo pelo qual o acesso do aldeão à condição de vizinho, por exemplo, não depende directamente da reversibilidade da sua situação de aldeão mas do local onde ele possui residência: "todo aldeano que casa ouvere en vila, seia vizino [...] e, si assi non fazere, non seia vinzino"45.

Falemos agora do que chamámos espaço de referência. Tradicionamente, corresponderá às zonas exteriores ao limite concelhio. Mas, como já vimos, do ponto de vista dos foros ele parece começar logo ali, para lá da

territórios, quando limítrofes". segundo a definição de Alexandre Herculano), da qual não temos evidências directas em Castelo Rodrigo mas está atestada numa série de cartas municipais aplicadas à Beira Interior que seguem o modelo de Salamanca, mostra bem que o investimento na cabeça do concelho não é incompatível com uma consciência da função delimitadora do termo concelhio. Sobre o "medianido": Alexandre Herculano, História de Portugal, notas críticas de José Mattoso, verificação do texto por Ayala Monteiro, 4 vols., Lisboa, 1980 (1 ed. 1846-1853), tomo IV, pp. 273-280.

${ }^{43}$ Foros de Castelo Rodrigo, IV, 23 (itálico nosso).

${ }^{+4}$ Foros de Castelo Rodrigo. III, 48.

${ }^{45}$ Foros de Castelo Rodrigo, II, 27. Esta disposição, que se encontra também em outros foros, mereceu a análise de José Luis Martín Martín para o caso de Cáceres, a partir do qual sustenta a ideia de que, apesar da existência desta norma. "fueron relativamente pocos los habitantes de las aldeas que alcanzaron la categoria de vecino", mantendo-se de forma nítida a oposição de interesses das aldeias face à vila |José Luís Martín Martín, La villa de Cáceres y sus aldeas en la Baja Edad Media (Nota sobre el origen y mantenimiento de una diferenciación socio-económica), "Norba", I (1980), pp. 209-218]. 
âmbito restrito da vila, pelo menos para determinados efeitos práticos; tivemos já oportunidade de nos referir a esse exterior imediato, intraconcelhio. Quanto ao espaço exterior propriamente dito, a sua representação é essencialmente ambivalente. Em princípio, tudo o que é de fora do concelho não suscita, por norma, grande especificação, sendo definido apenas a partir dessa condição alienígena. Efeito, provavelmente, da pouca inclinação da comunidade para a interacção com os elementos extrínsecos ao seu espaço próximo, desde que situados para lá de um raio de acção diminuto. Efeito, também, de alguma incapacidade em aceitar a integração concelhia em entidades mais abrangentes, sejam elas o espaço regional ou o Reino.

Este panorama só parece sofrer alterações em função das necessidades concretas da comunidade, fossem deslocações de carácter militar ou económico, ou direccionadas às justiças régias, as quais permitem considerar alguma hierarquia no espaço exterior ao termo concelhio. A sua representação no contexto dos foros processa-se então à imagem de uma série de círculos concêntricos, tendo a vila por ponto de referência, correspondendo cada um deles a esses momentos específicos de interacção entre a comunidade e o exterior - desde um círculo de relações próximo (referenciado pelos rios Côa, Águeda e Douro, e pelas localidades próximas de Sabugal, Alfaiates e Ciudad Rodrigo) até raios de acção mais distantes (um deles definido pela "linha" Coria-Salamanca-Alba-Toro-Zamora; outro, mais excêntrico, balizado por Plasencia e pelo rio Tejo $)^{46}$. A largueza deste último círculo de referências não deve espantar-nos, tal como não deve pôr em causa a pouca apetência deste espaço local para interacções distantes. $\mathrm{Na}$ verdade, todas estas localidades referenciam para o concelho de Castelo Rodrigo (e o mesmo se diga para a região de Riba-Côa) a geografia das expedições predatórias contra os muçulmanos praticadas sobremaneira nos séculos anteriores e, ao mesmo tempo, a geografia secular das rotas da transumância. Por esse motivo, a sua inclusão nos costumes municipais tem de certa forma um sentido de arcaísmo, não podendo invalidar a sensação de que no espaço concelhio de Castelo Rodrigo que temos vindo a analisar evoluíam grupos humanos essencialmente virados para dentro e pouco dados a abstracções espaciais como as que, em contrapartida, se detectam nos concelhos do Sul de Portugal, mais vocacionados para pensar a sua

\footnotetext{
${ }^{46}$ Foros de Castelo Rodrigo, I, 2 e 8; V, 40 e 74; VIII, 12, 15, 64, 66, 68 e 72.
} 
integração em espaços englobantes mais amplos, designadamente à escala do Reino ${ }^{47}$.

Quando, em 1297, o rei D.Dinis de Portugal e o rei D. Fernando IV de Castela fixarem, em Alcañices, o novo ordenamento espacial da área raiana, o concelho de Castelo Rodrigo, junto com as demais comunidades de Riba-Côa, conhecerá um novo enquadramento político, decorrente da sua integração no reino português.

Pouco se sabe sobre o verdadeiro impacto deste evento à escala local, mas é duvidoso que tenha acarretado para as comunidades raianas modificações estruturais do seu sistema organizativo. Para elas, o reino era ainda de algum modo, nesses finais do século XIII, uma abstracção. A fronteira, ou, pelo menos, a fronteira tal como a concebia o poder central, era-o também. Mais perto ficavam os limites reconhecidos como verdadeiramente referenciais: os que separavam a vila das aldeias, os que separavam o todo concelhio de tudo o que vinha de fora do concelho, e todos aqueles limites que, de forma genérica, organizavam o relacionamento entre as pessoas, hierarquizando a um tempo a sociedade e o espaço. Essas eram as fronteiras que importavam. Foi tendo-as por referente que o concelho de Castelo Rodrigo foi integrado no reino português. E foi dessa mesma forma que atravessou os séculos finais da Idade Média.

\footnotetext{
${ }^{47}$ Estipulam os foros de Santarém: que "todo vezino de Santarem que for penhorado [...] e se pedir depolo tercer dia prazo per avogado na vila, deveo aaver de tercer dia; e se o pedir para Guymaraees, deveo aaver de tres nove dias; e pera fora da vila, de dous nove dias; e pera fora do Reyno, de tres nove dias"; e, noutra ocasião: "costume he que a quem he posto daduzir vogado a dia asinaado e nom vem cum ele, nem quer demandar, que solvam a outra parte: $e$ esto he pelo Reyno" (respectivamente: Ineditos de Historia Portugueza, IV, p. 541; Idem, p. 554). Por seu lado, os costumes de Beja denotam em mais do que uma ocasião uma consciência do alinhamento dos costumes locais com as leis gerais, as do Reino: "Costume he de Beja, e de todo o reyno, que a carrega comprida é a da besta cavalar, e a meya carrega he da besta asnal" (Ineditos de Historia Portugueza, V. p. 491; exemplos idênticos a pp. 508 e 513). Ora, situaçóes como esta rareiam ao longo dos foros de Castelo Rodrigo, dando razão à interpretação de José Mattoso, para quem os homens de Alfaiates "não têm a consciência de pertencer a um organismo político; apenas reconhecem a sua dependência em relação ao poder incarnado na pessoa do rei" (Identificação de umm País. I, p. 441).
} 


\section{RÉSUMÉ}

Ce travail a pour objet l'analyse des mécanismes utilisés par l'aristocratie municipale pour assurer, dans le contexte du XIII ${ }^{\mathrm{emc}}$ siècle, la reproduction et le raffermissement d'un certain encadrement social et politique. Ayant pour base les nommés foros extensos de Castelo Rodrigo - pris, eux-mêmes, en tant qu'effort d'inteligibilité et d'intervention sur le sus-dit encadrement- et en accordant une attention particulière à la façon dont s'élaborent les identités d'inclusion et celles d'exclusion, on essaye le décodage du langage sociopolitique des foros.

\section{SUMMARY}

The purpose of the present work is to discuss the council aristocracy mechanisms' used to viabilize the consolidation of a certain socio-politic environment during the 13th century. On the basis of the so-called foros extensos from Castelo Rodrigo -understood, theirselves, as an understanding proposal, as well as a form of interference with the mentioned environment- and paying particular attention to the identity construction, both inclusive and exclusive, we try to decodify the socio-politic language of the foros. 